\title{
Relationship between Microstructure and Properties of Cu-Cr-Ag-(Ce) Alloy Using Microscopic Investigation
}

\author{
Huiming Chen, ${ }^{1,2}$ Dawei Yuan, ${ }^{2}$ Shanjiang Wu, ${ }^{2}$ Hang Wang, ${ }^{1}$ Weibin Xie, ${ }^{1}$ and Bin Yang ${ }^{1}$ \\ ${ }^{1}$ Institute of Engineering Research, Jiangxi University of Science and Technology, Ganzhou, China \\ ${ }^{2}$ School of Materials Science and Engineering, Jiangxi University of Science and Technology, Ganzhou, China \\ Correspondence should be addressed to Weibin Xie; x881109100@163.com and Bin Yang; yangbin65@126.com
}

Received 8 April 2017; Revised 29 May 2017; Accepted 7 June 2017; Published 10 July 2017

Academic Editor: Hendrix Demers

Copyright (c) 2017 Huiming Chen et al. This is an open access article distributed under the Creative Commons Attribution License, which permits unrestricted use, distribution, and reproduction in any medium, provided the original work is properly cited.

\begin{abstract}
Microstructure, precipitation hardening response, and mechanical and physical properties of $\mathrm{Cu}-\mathrm{Cr}-\mathrm{Ag}$ alloy and $\mathrm{Cu}-\mathrm{Cr}-\mathrm{Ag}-\mathrm{Ce}$ alloy have been investigated using transmission electron microscopy, scanning electron microscope, optical microscope, electrical conductivity analysis, and tensile test. The influence of element $\mathrm{Ce}$ on the matrix refinement, impurity removal, and precipitation in the $\mathrm{Cu}-\mathrm{Cr}-\mathrm{Ag}$ alloys has been analyzed. The experimental results show that the strength and electrical conductivity of Ce containing alloys are greater than those of Ce-free alloys after each processing step. Improvement of strength and electrical conductivity of the $\mathrm{Cu}-\mathrm{Cr}-\mathrm{Ag}$ alloy by adding Ce element is attributed to removing oxygen and sulfur from as-cast alloy.
\end{abstract}

\section{Introduction}

With the rapid development of high-speed electrified railway industry, there is urgent need to enhance the qualities of contact wire materials, including high conductivity, high strength, and moderate plasticity $[1,2]$. The $\mathrm{Cu}$-based alloys with low-chromium and low-silver are attractive candidates for contact wire materials due to the excellent performance of mechanical strength and electrical conductivity [3]. The excellent strength of the alloy is attributed to dispersion strengthening of $\mathrm{Cr}$ precipitates; and the high electrical conductivity of the alloy is due to the very low solubility of chromium and silver in copper solution [4].

Rare earth (RE) elements usually show many beneficial effects on microstructure and mechanical properties in conventional copper alloys $[5,6]$. Use of $\mathrm{RE}$ as microalloying elements in $\mathrm{Cu}$ has been studied for several years. Guo et al. [7] and Mao et al. [8] found that RE easily reacted with harmful elements to form intermetallic compounds, which resulted in purification of the alloy melts. Zhang et al. [9, 10] reported that $\mathrm{RE}$ elements have strong grain refining effects on the as-cast alloy by retarding the grain boundary motion in the process of grain growth, which can optimize the hot workability of the copper alloy. Trace addition of RE could effectively inhibit the growth of precipitates because RE atoms with large atomic radius distributed along the grain boundaries and dislocations would block the short range diffusion tunnel of the solute atoms [11, 12].

In the present work, trace Ce element was added to the $\mathrm{Cu}-\mathrm{Cr}-\mathrm{Ag}$ alloy; and microstructures and mechanical and physical properties of the $\mathrm{Cu}-\mathrm{Cr}-\mathrm{Ag}$ alloys with and without $\mathrm{Ce}$ were investigated. Influence of Ce element on the microstructure and properties was determined using microscopic investigation.

\section{Experimental}

The experimental alloys were melted in medium frequency induction furnace (ZP-45, Jiangyin Ruibang) using cathode copper, high purity silver, $\mathrm{Cu}-10 \mathrm{wt} \% \mathrm{Cr}$ master-alloy, and pure cerium and then cast into iron mold with $\Phi 80 \mathrm{~mm} \times$ $200 \mathrm{~mm}$ dimensions. The mean compositions of the experimental alloys were given in Table 1 . The real compositions were determined by an inductively coupled plasma emission spectrometer (ICP, IRIS Intrepid II, Thermo Fisher Scientific). The ingots were homogenized at $920^{\circ} \mathrm{C}$ for $1 \mathrm{~h}$ and then hot extruded into rod of $\Phi 12 \mathrm{~mm}$. Subsequently, the diameter of rods was reduced to $\Phi 4.5 \mathrm{~mm}$ by multipass cold drawing. 
TABLE 1: Mean composition for the experimental alloys.

\begin{tabular}{lcccc}
\hline \multirow{2}{*}{ Alloy } & \multicolumn{4}{c}{ Mean composition (wt.\%) } \\
& $\mathrm{Cr}$ & $\mathrm{Ag}$ & $\mathrm{Ce}$ & $\mathrm{Cu}$ \\
\hline $\mathrm{Cu}-\mathrm{Cr}-\mathrm{Ag}$ & 0.3 & 0.1 & - & $\mathrm{Bal}$ \\
$\mathrm{Cu}-\mathrm{Cr}-\mathrm{Ag}-\mathrm{Ce}$ & 0.3 & 0.1 & 0.025 & $\mathrm{Bal}$. \\
\hline
\end{tabular}

The cold drawn rods were solution treated at $950^{\circ} \mathrm{C}$ for $1 \mathrm{~h}$ and quenched in water to obtain supersaturated solid solution. Finally, the solution treated samples were annealed between $400^{\circ} \mathrm{C}$ and $550^{\circ} \mathrm{C}$ for durations between $30 \mathrm{~min}$ and $240 \mathrm{~min}$.

A standard metallographic technique was used to prepare the samples. This technique included wet grinding, prepolishing, "Minimet" polishing, and etching with a solution containing $20 \mathrm{~mL} \mathrm{HNO}_{3}$ in $80 \mathrm{~mL}$ water. An optical microscope (OM, BMM-90AE, Shanghai Bimu) and a scanning electron microscopy (SEM, MLA650F, FEI) were used to observe the microstructure of the samples. Grain size was measured through quantitative image analysis, based on American Society for Testing and Materials (ASTM) standard test method E112. The morphology and elemental distribution of the $\mathrm{Cu}-\mathrm{Cr}-\mathrm{Ag}$ alloy were examined by scanning electron microscopes (SEM, MIRA3 LMH, TESCAN-ORSAY HOLDING a.s.) equipped with energy-disperse spectrometer (EDS, 9806A-1UPS-SN, Thermo Fisher Scientific) attachment.

The specimens for TEM observation were sliced from bulk materials, ground into thin foils with $60 \mu \mathrm{m}$ thickness, and then punched into circle foils with a diameter of $3 \mathrm{~mm}$. The specimen foils were electropolished at $-35^{\circ} \mathrm{C}$ at a voltage of $40 \mathrm{~V}$ in a twin-jet electropolisher. The polishing solution was $30 \mathrm{vol} \%$ nitric acid and $70 \mathrm{vol} \%$ methanol. Subsequently, the foils were examined in a transmission electron microscopy (TEM, Tecnai-G2-F20, FEI) operating at $200 \mathrm{kV}$.

In addition, tensile tests were performed at room temperature on a universal testing machine (UTM5105X, Shenzhen Sunthink). The mechanical results reported in this study are the mean values of at least five specimens. Electrical conductivity was measured at room temperature by a direct current resistance tester (SB2230, Shanghai Guosheng). The conductivity was measured and evaluated according to the international annealing copper standard (IACS, 100\% IACS $=1.7241 \mu \Omega \cdot \mathrm{cm})$.

\section{Results}

3.1. Alloy Composition. Table 2 shows the real chemical compositions of the two alloys by ICP. Comparing Table 2 with Table 1, it is clear that the loss of $\mathrm{Ce}$ is high during melting of $\mathrm{Cu}-\mathrm{Cr}$-Ag alloy. It is indicated that the Ce element is easy to be consumed for reacting with other elements due to its active chemical properties. In addition, the Ce containing alloy has oxygen and sulfur contents of 0.0024 and $0.001 \mathrm{wt} . \%$, respectively. The contents of elemental $\mathrm{S}$ and $\mathrm{O}$ are decreased significantly by adding elemental $\mathrm{Ce}$. It is revealed that the oxygen and sulfur removing reaction takes place through the addition of Ce element, which could effectively purify the melt.
3.2. Microstructure. The microstructures of the $\mathrm{Cu}-\mathrm{Cr}-\mathrm{Ag}$ alloys under different treatment conditions are shown in Figure 1. The large as-cast grains of $\mathrm{Cu}-\mathrm{Cr}-\mathrm{Ag}$ alloy, about $460 \mu \mathrm{m}$ mean diameter, are observed in Figure 1(a). After hot extruding and cold drawing, the grains are obviously refined as shown in Figures 1(b) and 1(c). The grains become equiaxed after solid solution treatment due to the recrystallization (Figure $1(\mathrm{~d})$ ). The evolution of microstructure in $\mathrm{Cu}-\mathrm{Cr}$ $\mathrm{Ag}-\mathrm{Ce}$ alloy is similar to that in $\mathrm{Cu}-\mathrm{Cr}-\mathrm{Ag}$ alloy (Figures $1(\mathrm{e})-1(\mathrm{~h}))$.

Despite the same melting and casting processes, the ascast $\mathrm{Cu}-\mathrm{Cr}-\mathrm{Ag}$ alloys with or without Ce show different microstructures. The average grain diameter of as-cast $\mathrm{Cu}$ Cr-Ag-Ce alloy, about $340 \mathrm{um}$, is significantly smaller than that of as-cast $\mathrm{Cu}-\mathrm{Cr}-\mathrm{Ag}$ alloy. It is indicated that the $\mathrm{Ce}$ addition could refine the microstructure of the as-cast $\mathrm{Cu}$ $\mathrm{Cr}-\mathrm{Ag}$ alloy. On the one hand, Ce could react with $\mathrm{S}, \mathrm{O}$, and other elements forming high melting point compounds, and these compounds can increase the nucleation rate of grains. On the other hand, the corresponding atoms transport from the liquid phase to the solid phase is hindered, since Ce atoms segregate on the liquid-solid two-phase interface during solidification. Consequently, the growth of grains was prevented, and the grains became finer. However, the difference of grain sizes in the two alloys is reduced after hot extruding, cold drawing, and solution treatment. The average grain size of solution treated Cu-Cr-Ag-Ce alloy $(175 \mu \mathrm{m}$ in diameter) is very similar to that of solution treated $\mathrm{Cu}-\mathrm{Cr}$ Ag alloy (190 $\mu \mathrm{m}$ diameter). The $\mathrm{Cu}-\mathrm{Cr}$-Ag alloys with and without Ce element after solution treating exhibit similar morphology like grain shape and size, and the grain refining effect of Ce addition in $\mathrm{Cu}-\mathrm{Cr}-\mathrm{Ag}$ alloy is not obvious after forming and heat treatment.

The SEM micrographs of the $\mathrm{Cu}-\mathrm{Cr}-\mathrm{Ag}$ alloys under different treatment conditions are shown in Figure 2. It is revealed that these images of the $\mathrm{Cu}-\mathrm{Cr}-\mathrm{Ag}$ alloy and the $\mathrm{Cu}-\mathrm{Cr}-\mathrm{Ag}-\mathrm{Ce}$ alloy are similar. The coarse primary phases are observed in the matrix of the as-cast alloys (Figures 2(a) and $2(\mathrm{~d})$ ). The edges of primary phases are smoothed out during solution treating, which revealed that the primary phases can dissolve into the matrix at a high temperature $\sim 950^{\circ} \mathrm{C}$ (Figures 2(b) and 2(e)). However, the primary phases cannot entirely dissolve into the matrix after solution treating. The EDS investigations confirm that the undissolved primary phases in $\mathrm{Cu}-\mathrm{Cr}-\mathrm{Ag}$ alloy after solution treating are $\mathrm{Cr}$ particles (Figure 3). It is indicated that $\mathrm{Cr}$ particles tend to form during the solidification. In addition, the dispersed $\mathrm{Cr}$ precipitates cannot be observed in the SEM micrographs of the peak-aging alloys (Figures 2(c) and 2(f)). In order to observe the transformation process during aging, the detailed microstructural analysis was performed using TEM.

Figure 4 is the bright field TEM image showing the microstructure of the $\mathrm{Cu}-\mathrm{Cr}-\mathrm{Ag}-\mathrm{Ce}$ alloy aged at $500^{\circ} \mathrm{C}$ for $30 \mathrm{~min}$ and $120 \mathrm{~min}$. The TEM micrograph of aging-treated condition shows the presence of some fine precipitates in the matrix. Using selected area electron diffraction (SAED) technique (Figure 4(c)), the large particle with a bodycentered cubic structure (lattice parameter is about $0.292 \mathrm{~nm}$ ) could be identified as $\mathrm{Cr}$ precipitates. The average size of 
TABLE 2: Real compositions for the experimental alloys.

\begin{tabular}{lcccccr}
\hline \multirow{2}{*}{ Alloy } & \multicolumn{5}{c}{ Real composition (wt.\%) } \\
& $\mathrm{Cr}$ & $\mathrm{Ag}$ & $\mathrm{Ce}$ & $\mathrm{O}$ & $\mathrm{S}$ & $\mathrm{Cu}$ \\
\hline $\mathrm{Cu}-\mathrm{Cr}-\mathrm{Ag}$ & 0.29 & 0.082 & - & 0.0033 & 0.0032 & Bal. \\
Cu-Cr-Ag-Ce & 0.27 & 0.083 & 0.015 & 0.0024 & 0.001 & Bal. \\
\hline
\end{tabular}

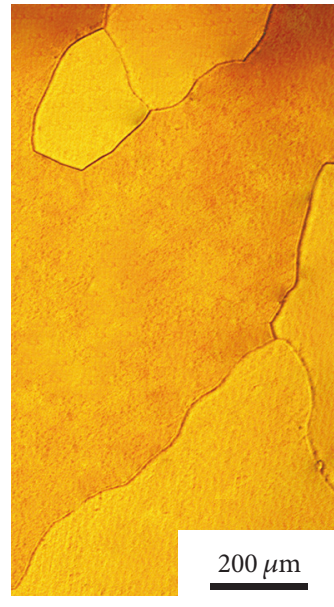

(a)

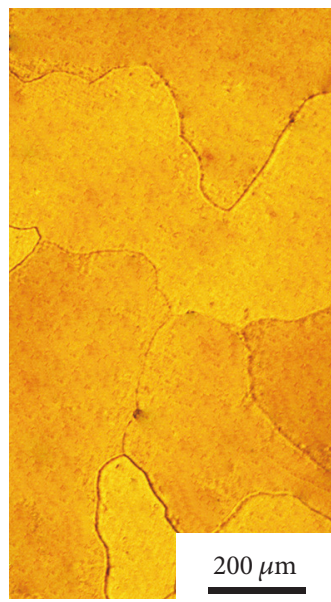

(e)

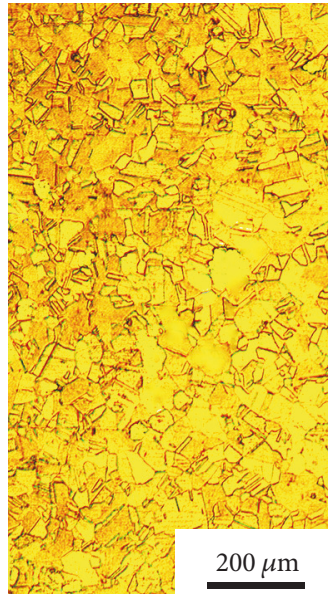

(b)

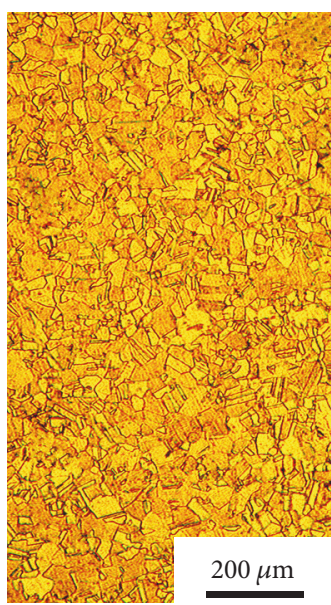

(f)

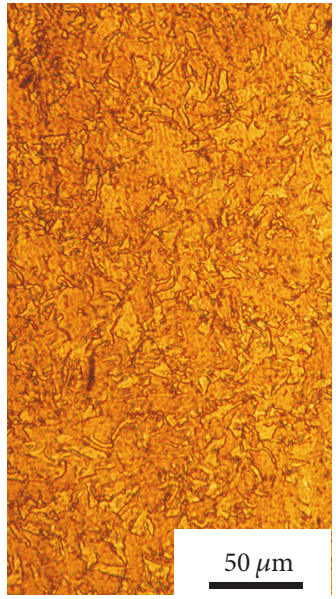

(c)

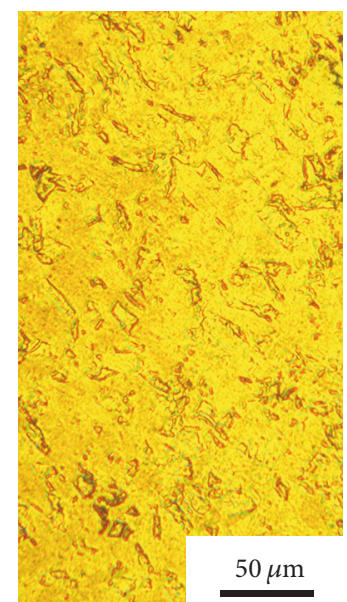

(g)

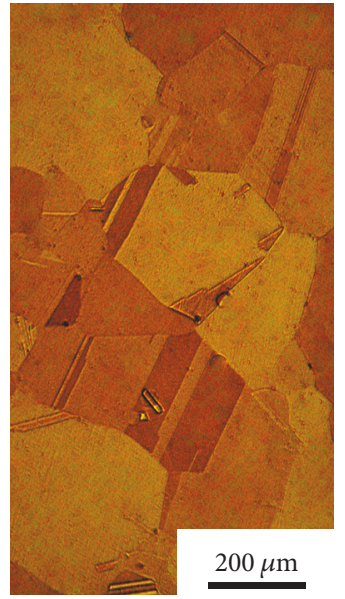

(d)

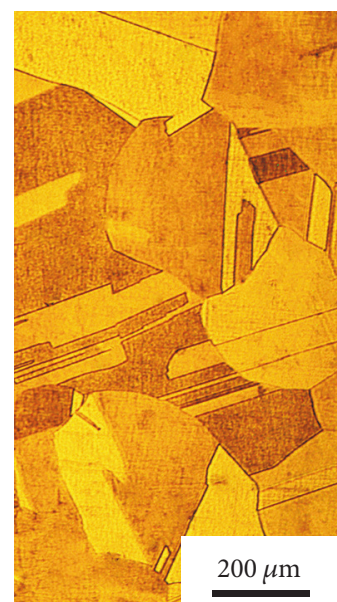

(h)

Figure 1: Optical micrograph of the Cu-Cr-Ag alloy (a-d) and Cu-Cr-Ag-Ce alloy (e-h) after different treatment: (a, e) as-cast alloy; (b, f) hot extruded alloy; (c, g) cold drawn alloy; (d, h) solution treated alloy.

Cr particles increased gradually with the increase of the aging time. The spherical precipitate size of peak-aged $\mathrm{Cu}-$ Cr-Ag-Ce alloy is about $55-70 \mathrm{~nm}$ aged at $500^{\circ} \mathrm{C}$ for $120 \mathrm{~min}$ (Figure 4(b)). Only spherical Cr particles are found within the grains in aged $\mathrm{Cu}-\mathrm{Cr}$-Ag-Ce alloy, which is similar to that observed in $\mathrm{Cu}$-Cr-Ag alloys and $\mathrm{Cu}-\mathrm{Cr}$ alloys $[4,13,14]$. It is indicated that the aging process is practically growing process of the $\mathrm{Cr}$ precipitate particles in $\mathrm{Cu}-\mathrm{Cr}-\mathrm{Ag}$-Ce alloy.

3.3. Mechanical and Physical Properties. The strengths and electrical conductivities of $\mathrm{Cu}-0.29 \mathrm{Cr}-0.082 \mathrm{Ag}$ alloy and $\mathrm{Cu}-0.27 \mathrm{Cr}-0.083 \mathrm{Ag}-0.015 \mathrm{Ce}$ alloy under various treatment conditions are shown in Figure 5. It can be seen that the strength of the $\mathrm{Cu}-0.29 \mathrm{Cr}-0.082 \mathrm{Ag}$ alloy ingot is increased due to the effect of work hardening after hot extruding and cold drawing. And the strength of this alloy is decreased due to recrystallization during solution treatment (Figure 5(a)). The variation trend of tensile strength in $\mathrm{Cu}-0.29 \mathrm{Cr}-0.082 \mathrm{Ag}$ alloy and $\mathrm{Cu}-0.27 \mathrm{Cr}-0.083 \mathrm{Ag}-0.015 \mathrm{Ce}$ alloy is consistent.

The lattice distortion or internal fault structure caused by deformation would hinder the migration of the electron. Thereby, the electrical conductivity decreases due to the introduction of defects like dislocations after hot extruding and cold drawing (Figure 5(b)). The dislocations and grain boundaries of the matrix become less due to recrystallization after solution treatment; therefore the electrical conductivity 


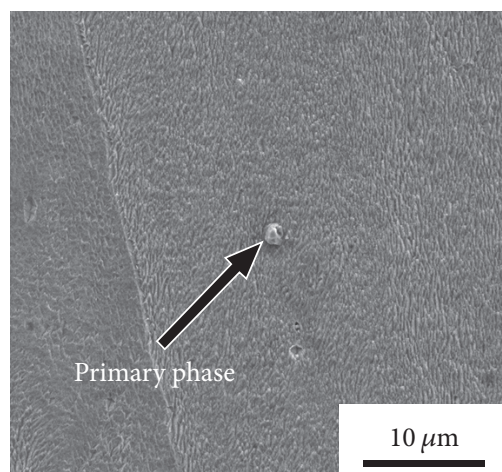

(a)

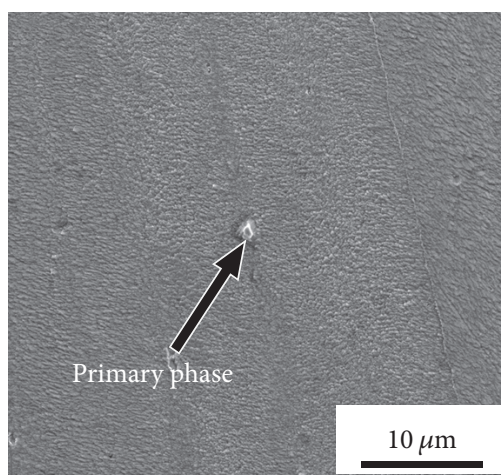

(d)

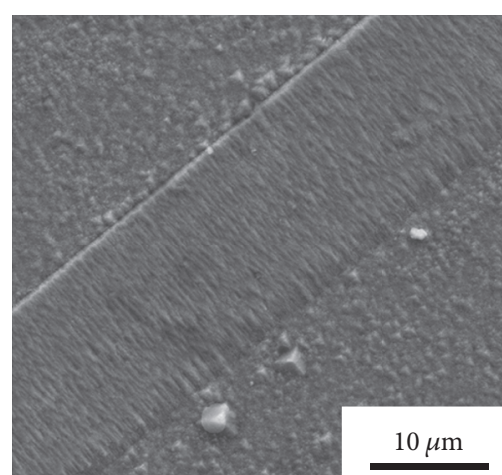

(b)

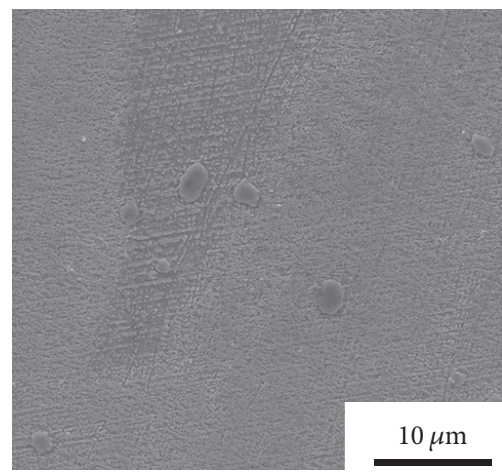

(e)

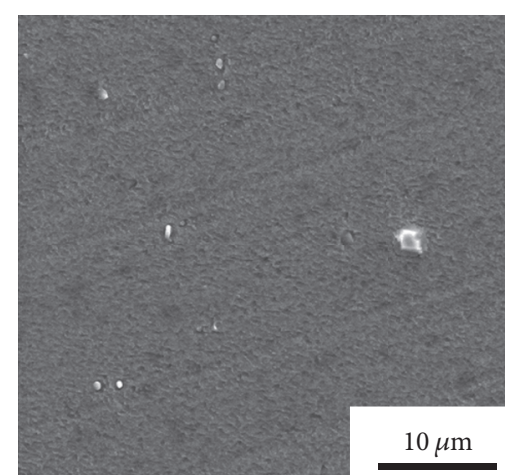

(c)

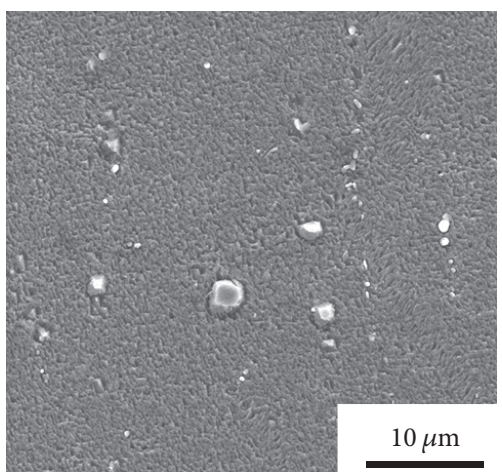

(f)

Figure 2: SEM micrograph of the Cu-Cr-Ag alloy (a-c) and Cu-Cr-Ag-Ce alloy (d-f) after different treatment: (a, d) as-cast alloy; (b, e) solution treated alloy; (c, f) aged alloy at $500^{\circ} \mathrm{C}$ for $120 \mathrm{~min}$.
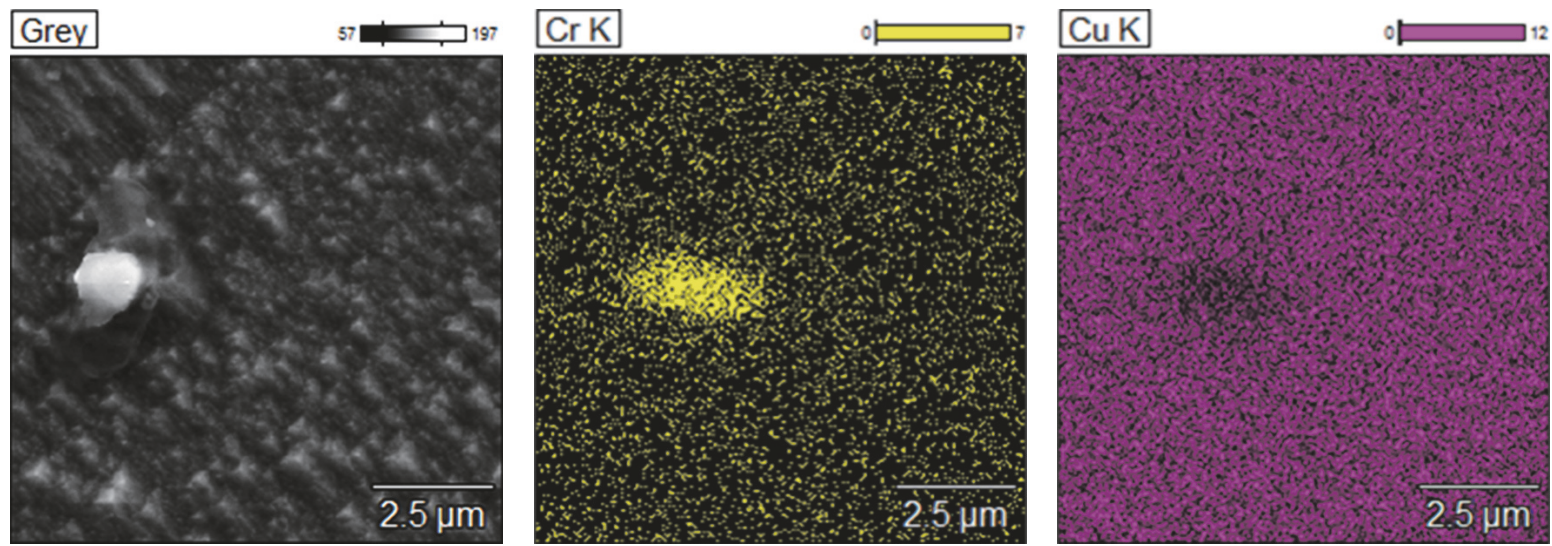

FIGURE 3: EDS mapping result of solution treated $\mathrm{Cu}-\mathrm{Cr}-\mathrm{Ag}$ alloy.

is $47.5 \pm 0.1 \%$ IACS after solution treatment in the $\mathrm{Cu}-\mathrm{Cr}$ Ag alloy (the errors of electrical conductivity are small, and error bars are neglected in figure of electrical conductivity). In addition, the strength and electrical conductivity of $\mathrm{Ce}$ containing alloy are always higher than Ce-free alloy under all treatment processes.

The variation of tensile strength with aging time and temperature for $\mathrm{Cu}-\mathrm{Cr}-\mathrm{Ag}$ alloys is shown in Figure 6. It can be observed that the strength of $\mathrm{Cu}-\mathrm{Cr}-\mathrm{Ag}$ alloys is increased rapidly with time in the initial stage and then gradually decreases. The strength of Cu-Cr-Ag-Ce alloy is improved with increasing $\mathrm{Cr}$ particle size during initial period of aging. The strength is gradually decreased by a progressive coarsening of Cr precipitates, which caused the overaging in the later stage of aging treatment process. It is indicated that the size and distribution of the precipitates exert a strengthening effect on mechanical properties. The maximum strengths of $\mathrm{Cu}-\mathrm{Cr}-\mathrm{Ag}$ alloys can reach a maximum at $500^{\circ} \mathrm{C}$. The result of mechanical properties change during aging treatment of $\mathrm{Cu}-\mathrm{Cr}-\mathrm{Ag}-\mathrm{Ce}$ alloy is consistent with that in $\mathrm{Cu}-\mathrm{Cr}-\mathrm{Ag}$ alloy. 


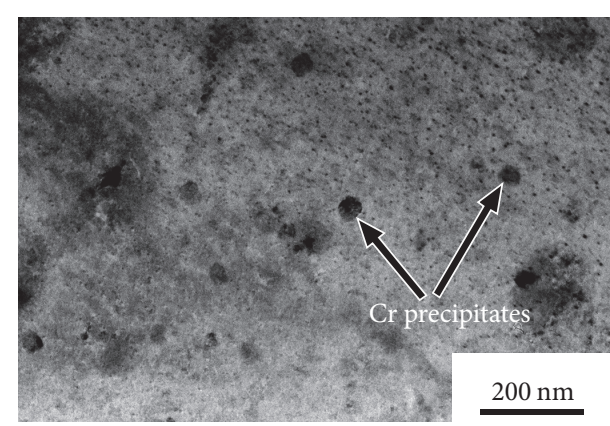

(a)

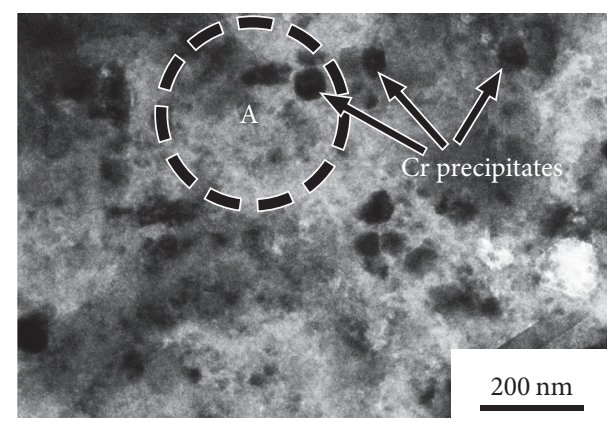

(b)

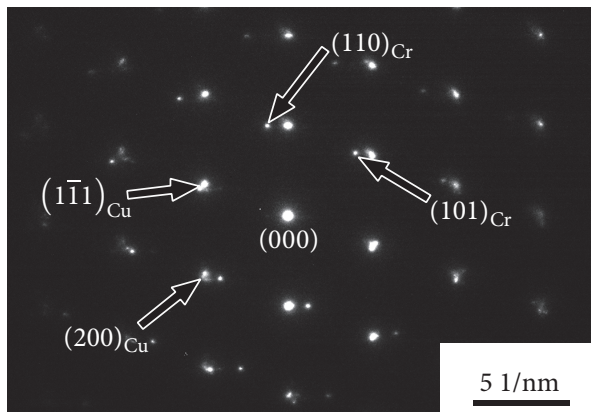

(c)

FiguRE 4: Bright field TEM microstructure of aged $\mathrm{Cu}-0.27 \mathrm{Cr}-0.083 \mathrm{Ag}-0.015 \mathrm{Ce}$ alloy: (a) aged alloy for $30 \mathrm{~min}$ at $500^{\circ} \mathrm{C}$; (b) aged alloy for $120 \mathrm{~min}$ at $500^{\circ} \mathrm{C}$; (c) the SAED pattern of area A.

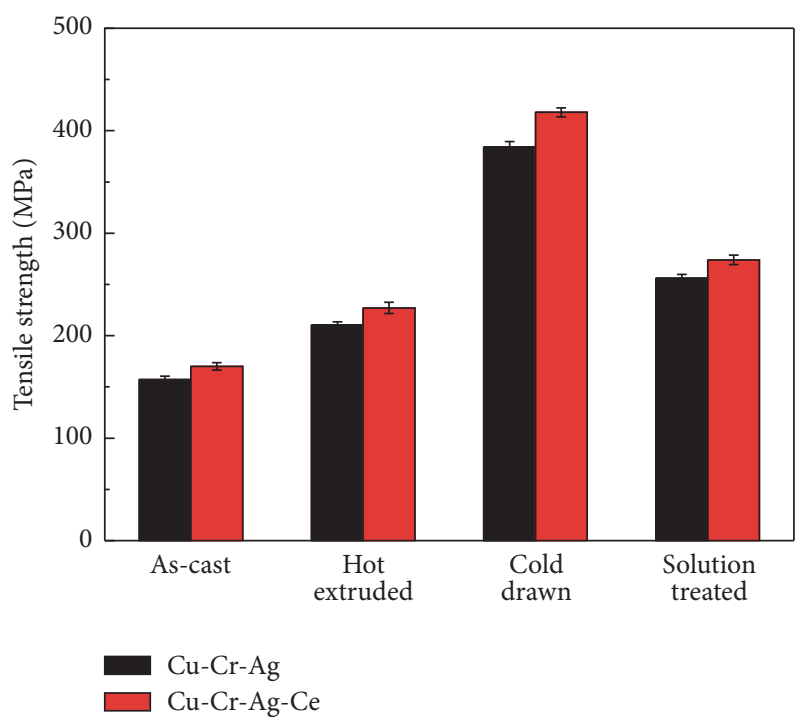

(a)

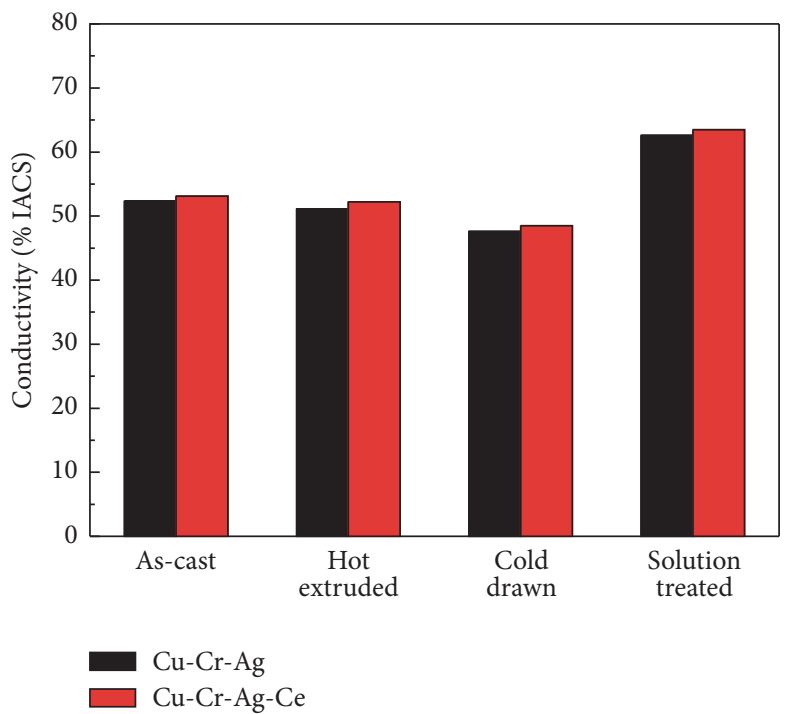

(b)

Figure 5: Mechanical and physical properties of $\mathrm{Cu}-\mathrm{Cr}-\mathrm{Ag}$ alloys after different treatments: (a) strength; (b) electrical conductivity.

However, the maximum strength of Ce containing alloy is always higher than Ce-free alloy at the same temperature. The maximum strength of $\mathrm{Cu}-\mathrm{Cr}-\mathrm{Ag}$ alloy and $\mathrm{Cu}-\mathrm{Cr}-\mathrm{Ag}$-Ce alloy aging at $500^{\circ} \mathrm{C}$ is $379 \mathrm{MPa}$ and $388 \mathrm{MPa}$, respectively.

The relation of the electrical conductivity and the aging conditions is plotted in Figure 7. It can be observed that the conductivity of the $\mathrm{Cu}-\mathrm{Cr}$-Ag alloys was improved with the increase of the aging time and temperature. The maximum electrical conductivity of $\mathrm{Cu}-\mathrm{Cr}-\mathrm{Ag}$ alloy and $\mathrm{Cu}-\mathrm{Cr}-\mathrm{Ag}-$ Ce alloy aging at $550^{\circ} \mathrm{C}$ is $95.0 \pm 0.2 \%$ IACS and $93.3 \pm$ $0.1 \%$ IACS, respectively. The electrical conductivity increases sharply and then tends to be stable during aging treatment. The dissolved solutes in pure copper will rapidly reduce due to $\mathrm{Cr}$ element precipitate from the $\mathrm{Cu}$-rich matrix, which induces the increase of electrical conductivity at the initial stage of aging. It is considered that the $\mathrm{Cr}$ element precipitates 


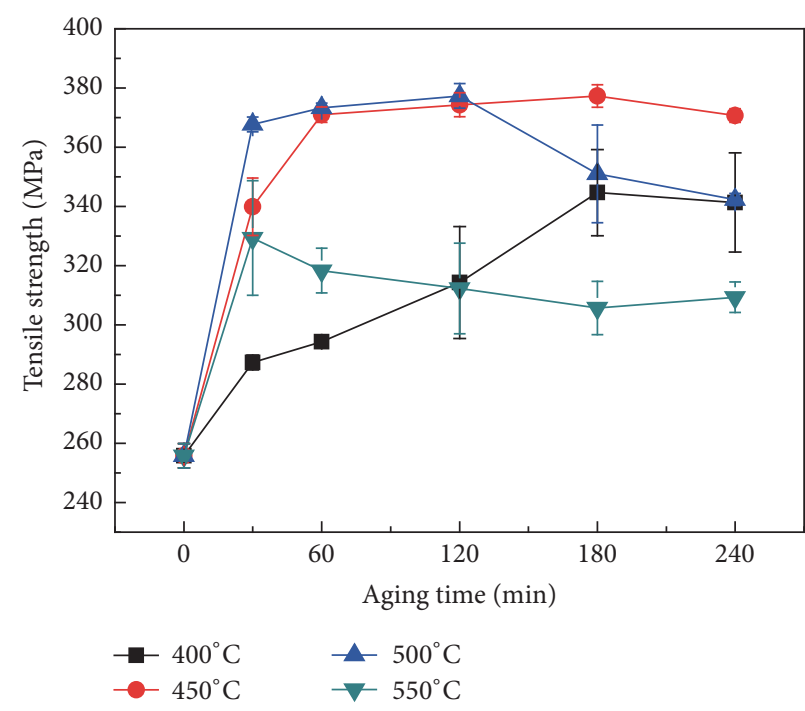

(a)

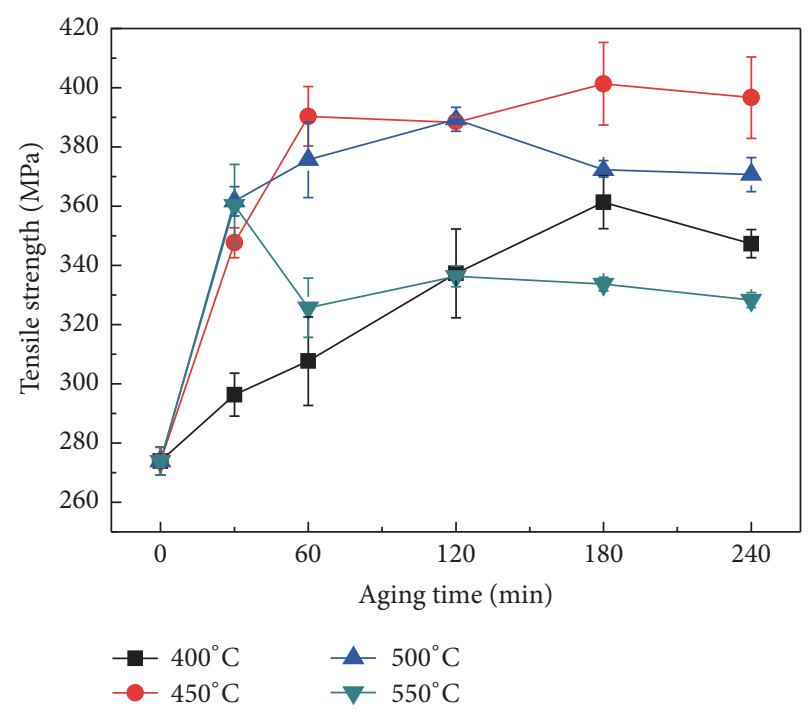

(b)

FIGURE 6: Tensile strength of aged experimental alloys: (a) Cu-0.29Cr-0.082Ag alloy and (b) Cu-0.27Cr-0.083Ag-0.015Ce alloy.

from supersaturated solid solution through diffusion of the solute atoms with the aid of the vacancies. Therefore, the $\mathrm{Cr}$ precipitation becomes slower due to the decrease of supersaturated vacancies in the later stage of aging treatment process. The precipitation transformation is kinetically controlled by diffusion. Therefore, the increase in conductivity at the initial stage is faster with increasing aging temperature, since the precipitation rate becomes higher at a higher temperature. In addition, the changing tendency of electrical conductivity of the $\mathrm{Cu}-\mathrm{Cr}-\mathrm{Ag}$ alloy and $\mathrm{Cu}-\mathrm{Cr}-\mathrm{Ag}-\mathrm{Ce}$ alloy is consistent.

\section{Discussion}

The present study shows that the addition of Ce affected the physical and mechanical properties in $\mathrm{Cu}-\mathrm{Cr}-\mathrm{Ag}$ alloy. It can be found that the conductivity of Ce containing alloy is always $1-2 \%$ IACS higher than Ce-free alloy, and the strength of Cefree alloy is always $15-30 \mathrm{MPa}$ higher than that of Ce-free alloy during forming and heat treating process. It is indicated that $\mathrm{Ce}$ addition could slightly improve the strength and electrical conductivity of $\mathrm{Cu}-\mathrm{Cr}-\mathrm{Ag}$ alloy.

The addition of $\mathrm{Ce}$ element can refine the microstructure of the as-cast $\mathrm{Cu}-\mathrm{Cr}$-Ag alloy. Nevertheless, the plastic deformation and heat treatment have significant effect on morphology like grain shape and size in $\mathrm{Cu}-\mathrm{Cr}-\mathrm{Ag}$ alloys. There is no significant difference in the grain size between $\mathrm{Cu}-\mathrm{Cr}-\mathrm{Ag}$ alloy and $\mathrm{Cu}-\mathrm{Cr}-\mathrm{Ag}-\mathrm{Ce}$ alloy during forming and heat treating process. It is revealed that the difference of properties between the two alloys is independent of grain size. The grain refining effect of $\mathrm{Ce}$ element on as-cast $\mathrm{Cu}-\mathrm{Cr}-\mathrm{Ag}$ alloy is not the main factor for the improvement of physical and mechanical properties. In addition, the differences of properties between the two alloys are stable during the whole process. It is indicated that the higher conductivity and strength in Ce containing alloy may be caused by the alloy composition.
The present study also shows that the sulfur and oxygen contents in $\mathrm{Cu}-\mathrm{Cr}-\mathrm{Ag}$ are reduced with the addition of $\mathrm{Ce}$ (Table 2). It is revealed that the $\mathrm{S}$ and $\mathrm{O}$ contents in $\mathrm{Ce}$ containing alloy are lower than that in the Ce-free alloy. The addition of $\mathrm{Ce}$ could deprive $\mathrm{O}$ and $\mathrm{S}$ elements from $\mathrm{Cu}-$ $\mathrm{Cr}-\mathrm{Ag}$ alloy. It is reported that $\mathrm{Ce}$ element is an element with high chemical activity, and the added Ce could react preferentially with $\mathrm{O}$ and $\mathrm{S}$ by forming high melting point and stable compounds during casting. The $\mathrm{CeS}, \mathrm{Ce}_{2} \mathrm{O}_{3}$, and $\mathrm{CeO}_{2}$ have lower densities, and it is easy to be removed with slag. The obstacles for the electron migration thus become less because the magnitude of $\mathrm{S}$ and $\mathrm{O}$ element in grain interiors and at grain boundaries is decreased. Therefore, the conductivity of Ce containing alloy is higher. In addition, the sulfur and oxygen elements are harmful for strength and plasticity $[15,16]$. For example, the embrittlement of copper is caused by sulfur impurity located at grain boundaries [16]. Therefore, the strength is increased with decreasing the oxygen and sulfur content in $\mathrm{Cu}-\mathrm{Cr}-\mathrm{Ag}$ alloy. It is revealed that the impurity removal effect of $\mathrm{Ce}$ element on $\mathrm{Cu}-\mathrm{Cr}$ Ag alloys is the main factor for the improvement of physical and mechanical properties during deformation and heat treatment.

Comparing the mechanical and physical properties of the $\mathrm{Cu}-\mathrm{Cr}-\mathrm{Ag}$ alloy and $\mathrm{Cu}-\mathrm{Cr}-\mathrm{Ag}-\mathrm{Ce}$ alloy during aging treatment, it is observed that the Ce addition has little effect on microstructure evolution and mechanical and physical properties. The morphology and growth regularity of $\mathrm{Cr}$ precipitates in $\mathrm{Cu}-\mathrm{Cr}-\mathrm{Ag}-\mathrm{Ce}$ alloy are consistent with those in $\mathrm{Cu}-\mathrm{Cr}-\mathrm{Ag}$ alloy. The changing tendency of strength and electrical conductivity in the $\mathrm{Cu}-\mathrm{Cr}-\mathrm{Ag}$ alloy and $\mathrm{Cu}-\mathrm{Cr}-\mathrm{Ag}-$ Ce alloy is similar. The element $\mathrm{Ce}$ will be distributed on both grain boundaries and defects of $\mathrm{Cu}-\mathrm{Cr}-\mathrm{Ag}$ alloy during solidification, due to the lower melting point of Ce and its large atomic radius [12]. However, the grain boundary migration and the reduction in internal crystal defect occurred 


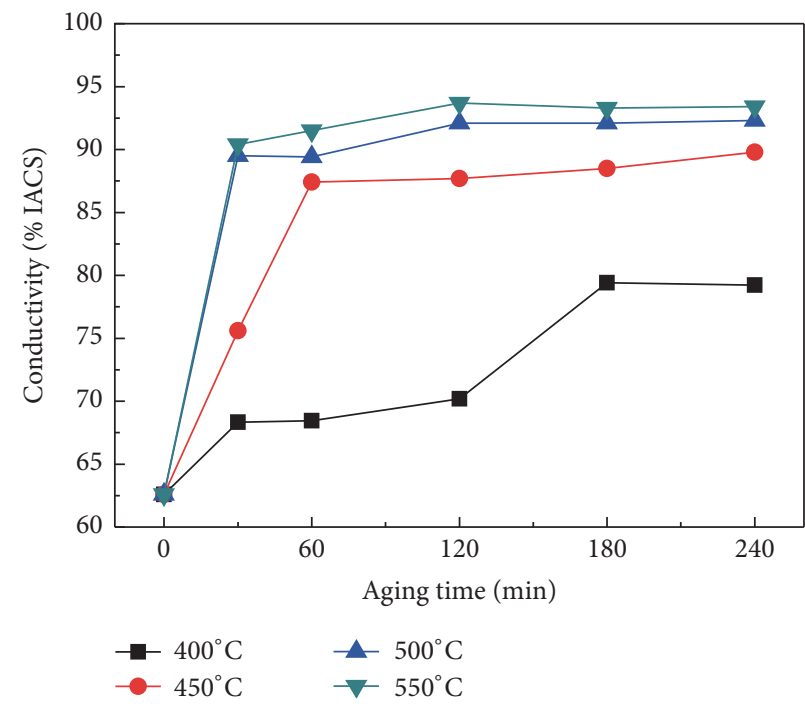

(a)

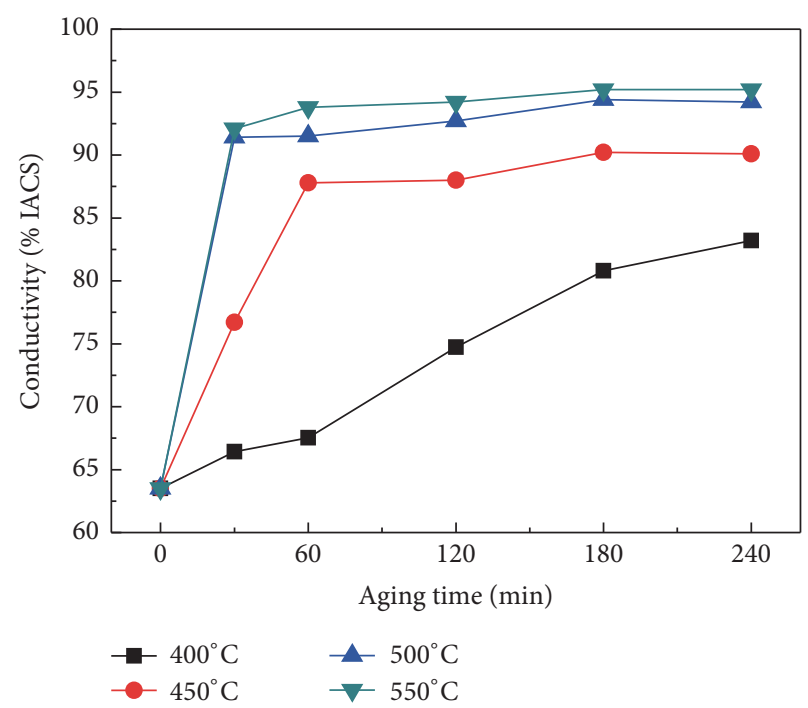

(b)

Figure 7: Electrical conductivity of aged experimental alloys: (a) Cu-0.29Cr-0.082Ag; (b) Cu-0.27Cr-0.083Ag-0.015Ce.

by recrystallization, which will result in decreasing of the amount of elemental Ce on the grain boundaries and defects [17]. Therefore, the Ce cannot effectively inhibit the growth of precipitates and refine the precipitates. There is a little effect on aging precipitation behavior by adding Ce element in the $\mathrm{Cu}-\mathrm{Cr}-\mathrm{Ag}$ alloy.

As discussed above, the main role of the added Ce during deformation and heat treatment in $\mathrm{Cu}-\mathrm{Cr}$-Ag alloy will not refine grains and precipitates but purify the melts. It should also be considered that the elimination of the impurities such as $\mathrm{O}$ and $\mathrm{S}$ could effectively increase strength and electrical conductivity of $\mathrm{Cu}-\mathrm{Cr}$-Ag alloy.

\section{Conclusion}

The effect of Ce element on microstructure and mechanical and physical properties of $\mathrm{Cu}-\mathrm{Cr}-\mathrm{Ag}$ alloy was investigated by optical microscope, scanning electron microscope, transmission electron microscopy, and mechanical tests. The role of Ce on the mechanical and physical properties was discussed. The following conclusions can be drawn from this work,

(1) The addition of Ce element in $\mathrm{Cu}-\mathrm{Cr}$-Ag alloy during melting can bring about deprivation of harmful elements such as $\mathrm{S}$ and $\mathrm{O}$ from melt and also refine the as-cast microstructure.

(2) The recrystallization will occur during solution treating due to severe plastic deformation, which results in the fact that the effects of Ce element on grain refining and precipitate refining are not apparent. The improvement of physical and mechanical properties in the Ce containing alloy during deformation and heat treatment is manly attributed to purification of $\mathrm{Cu}-\mathrm{Cr}-\mathrm{Ag}$ alloy by adding Ce during melting.

\section{Conflicts of Interest}

The authors declare that they have no conflicts of interest.

\section{Acknowledgments}

The present work is financially supported by the National Key Research and Development Program of China (Grant no. 2016YFB0301401). Thanks are also due to Mr. Mingmao Li, Dr. Xiangpeng Xiao, and Dr. Wenjing Wang for their help.

\section{References}

[1] G. Zhen, Y. Kim, L. Haochuang et al., "Bending fatigue life evaluation of $\mathrm{Cu}-\mathrm{Mg}$ alloy contact wire," International Journal of Precision Engineering and Manufacturing, vol. 15, no. 7, pp. 1331-1335, 2014.

[2] D. H. He, R. R. Manory, and N. Grady, "Wear of railway contact wires against current collector materials," Wear, vol. 215, no. 1-2, pp. 146-155, 1998.

[3] R. Mahmudi, A. Karsaz, A. Akbari-Fakhrabadi, and A. R. Geranmayeh, "Impression creep study of a Cu-0.3Cr-0.1Ag alloy," Materials Science and Engineering A, vol. 527, no. 10-11, pp. 2702-2708, 2010.

[4] S. G. Jia, M. S. Zheng, P. Liu et al., "Aging properties studies in a $\mathrm{Cu}-\mathrm{Ag}-\mathrm{Cr}$ Alloy," Materials Science and Engineering A, vol. 419, no. 1-2, pp. 8-11, 2006.

[5] J. B. Liu, L. Meng, and L. Zhang, "Rare earth microalloying in as-cast and homogenized alloys $\mathrm{Cu}-6$ wt.\% $\mathrm{Ag}$ and $\mathrm{Cu}-24$ wt.\% Ag," Journal of Alloys and Compounds, vol. 425, no. 1-2, pp. 185190, 2006.

[6] Z.-Y. Pan, J.-B. Chen, and J.-F. Li, "Microstructure and properties of rare earth-containing $\mathrm{Cu}-\mathrm{Cr}-\mathrm{Zr}$ alloy," Transactions of Nonferrous Metals Society of China (English Edition), vol. 25, no. 4, Article ID 63717, pp. 1206-1214, 2015. 
[7] F. A. Guo, C. J. Xiang, C. X. Yang, X. M. Cao, S. G. Mu, and Y. Q. Tang, "Study of rare earth elements on the physical and mechanical properties of a Cu-Fe-P-Cr alloy," Materials Science and Engineering B: Solid-State Materials for Advanced Technology, vol. 147, no. 1, pp. 1-6, 2008.

[8] X. Mao, F. Fang, J. Jiang, and R. Tan, "Effect of rare earth on the microstructure and mechanical properties of as-cast $\mathrm{Cu}-30 \mathrm{Ni}$ alloy," Rare Metals, vol. 28, no. 6, pp. 590-595, 2009.

[9] Z. Zhang, G. Lin, S. Zhang, and J. Zhou, "Effects of Ce on microstructure and mechanical properties of pure copper," Materials Science and Engineering: A, vol. 457, no. 1-2, pp. 313318, 2007.

[10] Y. Zhang, S. Huili, A. A. Volinsky et al., "Hot Deformation and Dynamic Recrystallization Behavior of the Cu-Cr-Zr-Y Alloy," Journal of Materials Engineering and Performance, vol. 25, no. 3, pp. 1150-1156, 2016.

[11] L. Huaqing, X. Shuisheng, M. Xujun, L. Yong, W. Pengyue, and C. Lei, "Influence of Cerium and Yttrium on Cu-Cr-Zr Alloys," Journal of Rare Earths, vol. 24, no. 1, pp. 367-371, 2006.

[12] F. Yu, J. Cheng, and X. Ao, "Aging characteristic of Cu-0.6Cr$0.15 \mathrm{Zr}-0.05 \mathrm{Mg}-0.02 \mathrm{Si}$ alloy containing trace rare earth yttrium," Rare Metals, vol. 30, no. 5, pp. 539-543, 2011.

[13] A. Chbihi, X. Sauvage, and D. Blavette, "Atomic scale investigation of Cr precipitation in copper," Acta Materialia, vol. 60, no. 11, pp. 4575-4585, 2012.

[14] S. C. Krishna, G. S. Rao, A. K. Jha, B. Pant, and P. V. Venkitakrishnan, "Strengthening in high strength $\mathrm{Cu}-\mathrm{Cr}-\mathrm{Zr}$ Ti alloy plates produced by hot rolling," Materials Science and Engineering A, vol. 674, pp. 164-170, 2016.

[15] D. Guskovlć, D. Marković, and S. Nestorovlć, "Effect of deformation and oxygen content on mechanical properties of different copper wires," Bulletin of Materials Science, vol. 20, no. 5, pp. 693-697, 1997.

[16] E. I. Krupnikova-Perlina, L. I. Sotnikova, S. A. Kuznetsova, V. A. Bliznyuk, and V. G. Osintsev, "Effect of sulfur on the properties of copper," Metal Science and Heat Treatment, vol. 27, no. 3, pp. 223-225, 1985.

[17] R. J. McCabe and D. F. Teter, "Analysis of recrystallized volume fractions in uranium using electron backscatter diffraction," Journal of Microscopy, vol. 223, no. 1, pp. 33-39, 2006. 

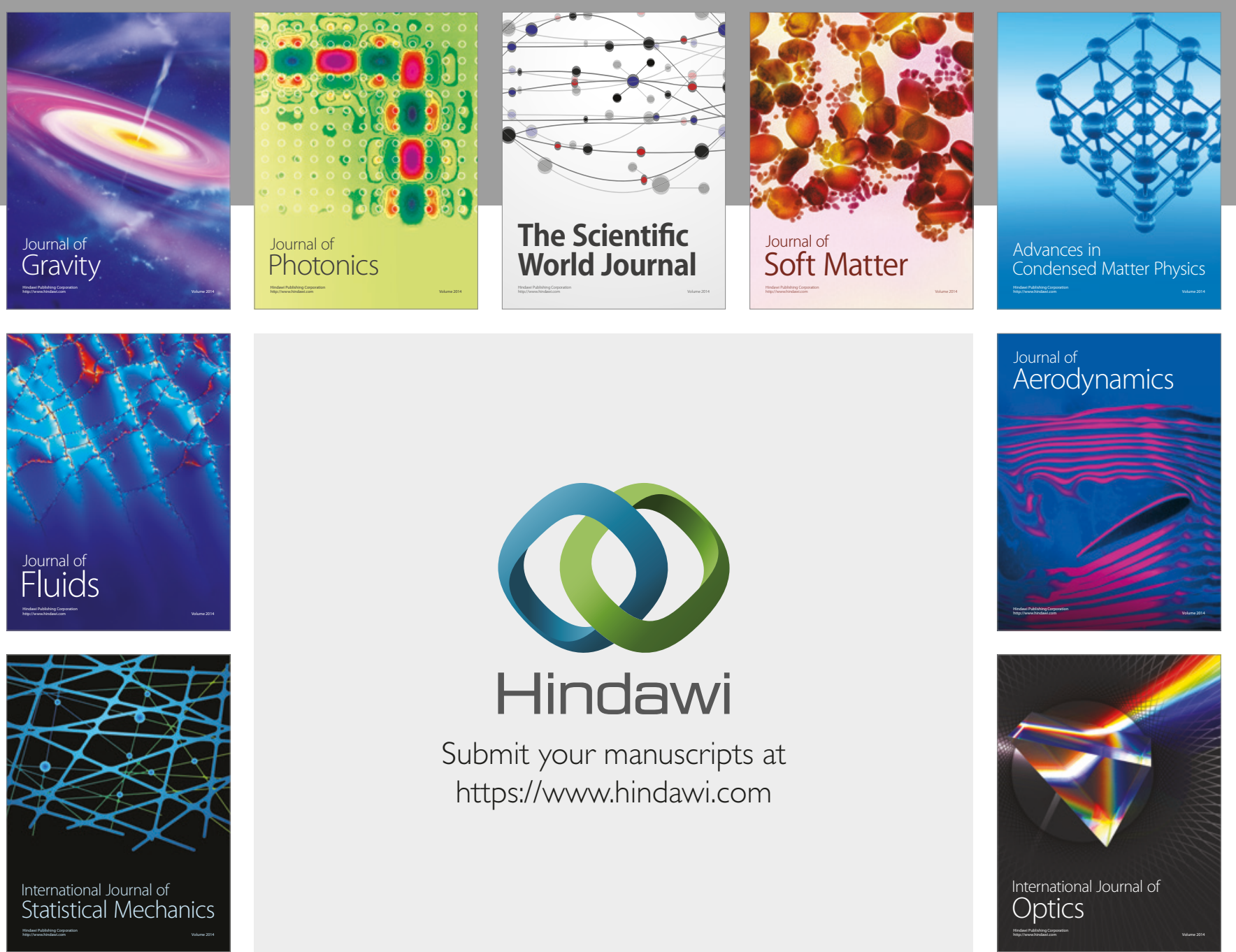

Submit your manuscripts at

https://www.hindawi.com
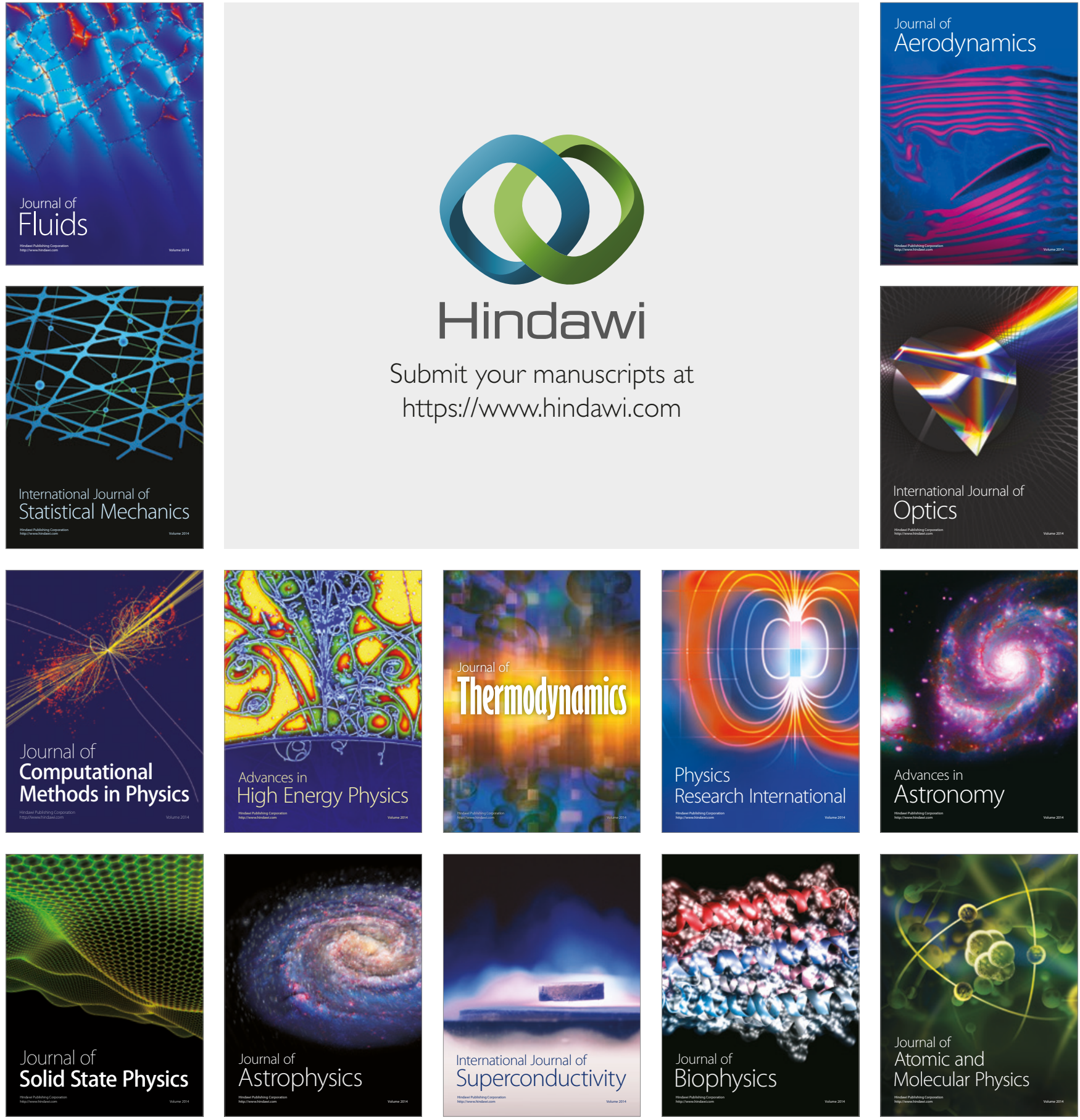